\title{
Culturas originárias e turismo: uma experiência de turismo comunitário no mundo Mapuche, Tralcao, Sul do Chile ${ }^{1}$
}

\author{
Indigenous cultures and tourism: an experience in community based \\ tourism in the Mapuche world, Tralcao, Southern Chile
}

\section{Christian Eduardo Henríquez Zuñiga, Marisela Pilquiman Vera, Juan Carlos Skewes, Carlos Alberto Cioce Sampaio}

\begin{abstract}
RESUMO
A revitalização de espaços e elementos simbólicos, conjuntamente a governança de territórios habitados é uma prioridade dos povos originários da America Latina, diante de uma historia de repressão cultural. Estes, por sua vez, tentam conservar elementos próprios de sua cultura. Contudo, esse esforço não é tarefa fácil quando há o predomínio da cultura ocidental, pretensiosamente homogênea, com traços urbanos e materialistas. Os Mapuches se encontram em uma situação de precariedade no Chile, são discursivamente descontextualizados e desterritorializados. A problemática esta dada pelas disputas e imposições sobre uso e acessos a recursos naturais, neste caso, a qualidade da água, o que altera e condiciona a cotidianidade da comunidade indígena. Neste contexto o presente trabalho objetiva dar conta de uma experiência na qual se procurou avançar na identificação e priorização das demandas da comunidade de Tralcao para respondê-las a partir de uma proposta de turismo de base comunitária (TBC). Metodologicamente, trabalhou-se com pesquisa-ação participante, a partir de oficinas e observações de campo. Realizou-se um transecto com estudantes do ensino médio que participam do Projeto Pré-Honra de Ecolíderes, universitários que compõem o Programa de Honra em Meio Ambiente e Desenvolvimento Humano Sustentável, no âmbito da Universidade Austral do Chile, e membros da comunidade indígena de Tralcao. O transecto baseia-se na coleta de dados ao longo de uma caminhada de reconhecimento do território mediante observações sistemáticas sobre modos de vida e biodiversidade. O eixo articulador do turismo de base comunitária (TBC) se sustentou a partir da comunidade, convivialidade e cotidianidade mapuche, na qual se deseja conservar seus modos de vida e preservar a biodiversidade territorial, construindo de maneira solidária propostas de turismo como alternativa para resgatar, difundir e conservar o mundo mapuche. Não se deseja transformar comunidades em aldeias paradisíacas, no sentido de espetacularizá-las. O TBC pode ser utilizado como um arranjo pedagógico que melhor qualifica a educação ambiental, no sentido de formar cidadãos proativos, ao contrário de seres passivos, utilizando-se de trilhas interpretativas de paisagens naturais associadas a paisagens construídas.
\end{abstract}

PALAVRAS-CHAVE: Turismo de Base Comunitária; Comunidades Mapuche; Hospitalidade; Cotidianidade. 
Culturas originárias e turismo: uma experiência de turismo comunitário no mundo Mapuche, Tralcao, Sul do Chile.

\begin{abstract}
The revitalization of the symbolic spaces and elements, along with the governability of the inhabited territories, are a priority among the original peoples of Latin America who try retain their identity in the context of a history of cultural repression, who try to retain their identity. However, such an effort is far from easy under the hegemony of a Western culture that aims to impose homogeneity, materialism and urbanism to indigenous societies. The Mapuche live under a situation of vulnerability in Chile, discursively decontextualized and deterritorialized. The problem arises from the disputes and restrictions over access and use of natural resources, and, in this case, over the quality of water that conditions and modifies indigenous community everyday life. In this context, this paper informs about an experience through which it was aimed to create instances to identify, promote and prioritize the Tralcao community's claims, while generating new ways of inter and transdiciplinary knowledge to confront such claims including a proposal of community based tourism (CBT) as a practical engagement in the process. This experience was worked by means of participatory research and office work and field observations. With a group of high school and university students along with members of the local community, a transect was designed and studied. Participants of this experience were students of the Honors Program in environmental Studies of the Universidad Austral de Chile, the Pre-Honors Project of Eco Leaders, and the community of Tralcao. The transect consisted in the gathering of environmental information through a walk of recognition of the community territory about the ways of life and biodiversity. Community based tourism is inspired by hospitality, everyday life and sharing and it aims the conservation of local ways of life and the protection of biodiversity. It ambitions to design tourism as a strategy for rescuing, disseminating and conserving the Mapuche world. It avoids, however, the exhibition of such world as paradisiacal. The CBT may be used as a pedagogical method for providing environmental education, thus, contributing to the formation of citizens rather than passive individuals. In so doing, it recognizes the signals that are inscribed in the natural landscapes associated with the built environment.
\end{abstract}

KEYWORDS: Community Based Tourism; Mapuche Communities; Hospitality; Everyday Life.

\title{
Introdução
}

Tudo parece indicar que as discussões relacionadas ao uso, apropriação e transformação de territórios que tratam do patrimônio natural ou cultural tem progressivamente sensibilizado - embora minoritariamente - certos segmentos da sociedade planetária que prospectam alternativas de desenvolvimento onde se busca a simbiose entre conservação de modos de vida tradicionais e preservação da biodiversidade (HENRÍQUEZ; PILQUIMAN; SKEWES, 2011).

A revitalização de espaços e elementos simbólicos, conjuntamente a governança de territórios habitados é uma prioridade de povos originários da America Latina, 
diante de uma historia de repressão cultural.

Estes, por sua vez, tentam conservar elementos tangíveis e intangíveis próprios de sua cultura. Contudo, esse esforço não é tarefa fácil quando há o predomínio da cultura ocidental, pretensiosamente homogênea, com traços urbanos e materialistas.

No caso do Chile, a reivindicação de povos originários, e especificamente dos Mapuches, não é diferente desse quadro apontado, pois nem sempre suas demandas têm encontrado uma boa acolhida na sociedade chilena. Os Mapuches se encontram em uma situação de precariedade, são discursivamente descontextualizados e desterritorializados.

A cosmovisão mapuche sacraliza a relação dos seres humanos com a natureza reconhecendo nela a presença de seres guardiões que a protegem: os ngen e demais entidades (FOERSTER, 1993; GREBE, 1986, 1993-4, 2000). Os seres humanos devem obediência e respeito aos fenômenos naturais de maneira que não sofram com as consequências do manejo inapropriado (GREBE, 1993-4, 2000). A cosmovisão se encarna nos mitos e nas práticas rituais através das quais se conserva sua memória.

O valor principal que regula a relação com a natureza é a de respeito e reciprocidade: os seres humanos têm de pedir permissão aos diversos espíritos para se apropriar de seus recursos (ALONQUEO 1979; GREBE 2000). As ações desrespeitosas desagradam aos Ngen ou despertam na natureza suas forças para restabelecer a resiliência. As catástrofes são, neste sentido, a resposta da natureza a uma ação humana depredadora.

Os mitos, ritos e práticas propiciatórias inclusas na cosmovisão mapuche podem ser entendidas como um meio transcendental através do que a humanidade se encarna na natureza, estabelecendo com ela um vínculo simbiótico (SKEWES et al., 2011). Fecha-se assim o círculo de uma comunidade humana e não humana enraizada numa só e mesma totalidade.

Esse contexto faz surgir a problemática de que as disputas e imposições sobre uso e acessos a recursos naturais, no caso deste artigo, a qualidade da água, altera e condiciona a cotidianidade da comunidade indígena. $O$ presente trabalho objetiva dar conta de uma experiência na qual se procurou avançar na identificação e priorização das demandas da comunidade de Tralcao para respondê-las a partir de uma proposta de turismo de base comunitária.

Tais discussões se contextualizam na temática do desenvolvimento sustentável onde é possível encontrar diferentes tipologias de turismo, como por exemplo, o turismo comunitário ou de base comunitária, que aposta na perspectiva intercultural para a inserção das economias comunitárias. Contudo não considera a economia o principal aporte e sim a valorização dos modos de vida tradicionais e preservação da biodiversidade (SAMPAIO, 2005; PILQUIMÁN; SKEWES, 2009; 2010).

As discussões que vem sendo feitas a atividade do turismo precisam ser meIhores compreendidas, tais como: migração da população autóctone para áreas peri- 
Culturas originárias e turismo: uma experiência de turismo comunitário no mundo Mapuche, Tralcao, Sul do Chile.

féricas, diante da venda de suas propriedades cotejadas pela especulação imobiliária ou por forâneos, descaracterização de modos de vida diante da atividade de trabalho e renda originada pelo turismo, além de outras. Neste sentido, surge uma abordagem denominada turismo de base comunitária (TBC), de inspiração interdisciplinar, que caminha rumo à transdisciplina, o que caracteriza o turismo como fenômeno humano, podendo sugerir uma abordagem simultaneamente preventiva e proativa.

Os problemas mais significativos contemporâneos não serão resolvidos de maneira disciplinar, isto é, por especialistas. Muitos se tornaram problemas exatamente por terem sido tratados de maneira unidisciplinar. O desafio do método interdisciplinar é desfazer o feitiço que se tem pela especialização. Enfim, é uma método de construção de conhecimento partindo de uma problemática/complexidade de ensinoaprendizagem/pesquisa/extensão que se deseja compreendê-la bem como resolvê-la, podendo inclusive criar novos campos de conhecimento (característica da transdisciplina) que até, então, não se faziam necessários ou que surgiram de conexões de disciplinas e de seus desdobramentos que ainda não existiam (CA-CiAmb, 2011).

De fato ao aprofundar o modelo de desenvolvimento e suas implicações quanto ao fenômeno turismo pode-se referenciar um modelo mais conservador, instalado predominantemente em territórios litorâneos, onde vale a lógica da máxima rentabilidade no menor espaço e tempo possível (CROSBY; PRATO, 2009). Sob esta perspectiva evidenciam-se aspectos que condicionam a sustentabilidade dos destinos turísticos, como capacidade de carga ou tolerância social, por exemplo, que raramente são considerados neste modelo. Assim como propõe Sampaio (2005), a lógica do modelo de turismo de massa se funda na privatização de lucros de curto prazo e socialização dos prejuízos socioambientais de médio e longo prazo, ocasionando discussões como as exemplificados anteriormente.

\section{Metodologia}

O artigo é produto do projeto Fondecyt F-1090465, "Paisajes del Agua, Prácticas Sociales y Sustentabilidad en la Cuenca Hidrográfica del Río Valdivia", no qual uma equipe de professores, pesquisadores e estudantes vem trabalhando distintas comunidades que vivem às margens da bacia hidrográfica do rio Valdivia, Região dos Rios, Chile.

A metodologia empregada foi a pesquisa-ação participante, a partir de oficinas e observações de campo (GADGIL, 2000). Realizou-se uma caminhada ao longo de um transecto com 12 estudantes do ensino médio (2 homens e 10 mulheres) que participam do Projeto Pré-Honra de Ecolíderes e 20 universitários (11 homens e 9 mulheres) que compõem o Programa de Honra em Meio Ambiente e Desenvolvimento Humano Sustentável, no âmbito dos cursos Filosofias do Desenvolvimento e Reflexões sobre a Sustentabilidade, ambos oferecidos pela Universidade Austral de Chile, e ainda com 10 membros da comunidade indígena de Tralcao (3 homens e 7 mulheres) (Tabela 1). 
Zuñiga, C.E.H.; Vera, M.P.; Skewes, J.C.; Sampaio, C.A.C.

Tabela 1: Conformação da amostra participante.

\begin{tabular}{|l|c|c|c|c|}
\hline \multicolumn{1}{|c|}{ Estrato } & Mulheres & Homens & Faixa etária & Total \\
\hline $\begin{array}{l}\text { Estudantes de ensino médio } \\
\text { (Pré- Honra) }\end{array}$ & 10 & 2 & 16 a 18 anos & 12 \\
\hline $\begin{array}{l}\text { Curso Filosofias do Desen- } \\
\text { volvimento }\end{array}$ & 8 & 8 & 21 a 25 anos & 16 \\
\hline $\begin{array}{l}\text { Curso Reflexões sobre a } \\
\text { Sustentabilidade }\end{array}$ & 1 & 3 & 21 a 25 anos & 4 \\
\hline Atores locais & 7 & 3 & 30 a 60 anos & 10 \\
\hline Total & $\mathbf{2 6}$ & $\mathbf{1 6}$ & & 42 \\
\hline
\end{tabular}

Fonte: Os autores.

O transecto baseia-se na coleta de dados ao longo de uma caminhada de reconhecimento do território, mediante observações sistemáticas sobre modos de vida e biodiversidade. Isto é, na literatura específica do ecoturismo, trilha interpretativa. Através de conversas informais, vão se coletando dados empíricos que sustentam a pesquisa (SEIXAS, 2005). Posteriormente, se desenvolvem oficinas participativas onde se priorizam as informações coletadas no transecto e é a própria comunidade que problematiza.

\section{Turismo e suas Interações}

Quando se tenta construir uma crítica à atividade turística, geralmente, se tem como ponto de partida os conflitos que esta gera ao meio ambiente e/ou às relações sociais com as comunidades autóctones onde se desenvolve, conforme o padrão de racionalidade/ modernidade que pressupõe o turismo. No entanto, há um movimento de vanguarda, sob a denominação turismo de base comunitária (TBC), o qual herda o diálogo iniciado pelo Encontro Nacional de Turismo de Base Local (ENTBL), que compreende o turismo como fenômeno humano.

A denominação TBC surge a partir de modalidades do turismo geralmente desenvolvidas no espaço rural/costeiro, conhecidas também pelos termos turismo cultural ou etnoturismo, ecoturismo e agroturismo, que a priori se mostram mais vanguardistas, no entanto, na maioria dos casos, são apropriadas pela lógica/racionalidade econômica (SAMPAIO, 2005; 2010). O etnoturismo, muitas vezes, é pensado sobre esta lógica quando é compreendido mais pela exoticidade, no sentido de espetacularização, do que pela autenticidade (SMITH, 1992). De fato, no cenário mundial o turismo cultural tem sido uma das alternativas mais privilegiadas para dinamizar economias locais, dado o interesse ou fetiche ao redor do autóctone que o consumidor de turismo possui, desejo de experimentar outra cotidianidade, ao invés das suas (PILQUIMÁN; SKEWES, 2009; 2010). 
Culturas originárias e turismo: uma experiência de turismo comunitário no mundo Mapuche, Tralcao, Sul do Chile.

O turismo comunitário se apóia em três conceitos chaves (HENRÍQUEZ et al., 2009): (a) comunidade; (b) convivencialidade; e (c) cotidianidade.

\section{Comunidade}

A palavra comunidade etimologicamente se apresenta com significado positivo. Comunidade é percebida como um lugar cálido e confortável. A comunidade, não obstante, está exposta a fissura e riscos associados ao posicionamento desigual de seus membros em relação do meio social. No entanto, os vínculos fundados na confiança protegem o grupo, promovendo um sentido de segurança baseado no pertencimento. Fora da comunidade existem muitos perigos. Tudo parece indicar que numa comunidade é possível encontrar a hospitalidade, e é neste sentido que se pode orientar propostas alternativas ao turismo convencional, tal como o turismo de base comunitária (BAUMAN, 2003).

\section{Convivencialidade.}

O conceito de convivencialidade pode ser entendido como uma relação social na qual há interesse de um sujeito pelo outro, pela busca da alteridade, pelo diferente, pela autenticidade, respeitando os modos de vida que lhe são próprios, independente se podem ser caracterizados como modernos ou antiquados. Há respeito pelos hábitos, modos de falar, cantar, dançar, comer, ou seja, pela cultura. A relação estabelecida entre os visitantes e os visitados supera a visão de negócio, o que possibilita estabelecer um diálogo intercultural, que resgata, reconstrói e promove a interconectividade entre cosmovisões que conjugam diferentes tipos de tecnologias - alta tecnologia com apropriadas -, saberes - científico com popular -, e culturas - ocidentalizadas com tradicionais (ILLICH, 1976; IRVING; AZEVEDO, 2002; CORIOLANO; LIMA, 2003; SAMPAIO, 2005). Ademais, a convivencialidade potencializa espaços socioprodutivos coletivos - não economicistas -, que podem ser chamados de ecossocioeconômicos, como, por exemplo, clubes ou feiras de trocas, plataformas de comércio justo).

\section{Cotidianidade}

Este conceito considera aspectos fundamentais das populações como é o uso do tempo e do espaço, as formas de organização do trabalho, o consumo de bens materiais e simbólicos, as formas e os meios de comunicação e tecnologias adotadas por essas populações em sua realidade cotidiana. Finalmente, contempla essas e outras mediações culturais que são importantes para o entendimento das culturas (LIMA, 2004).

\section{A experiência de Tralcao}

Tralcao é uma localidade cujo nome epistemologicamente deriva da expressão tralkan, que significa em mapuzungun (língua do povo Mapuche) lugar de trovões, ainda que seus habitantes tradicionalmente o traduzam como "escopeta", provavelmente associado ao som que esta emite (SAMPAIO, 2010). Localiza-se no coração do Santuário da Natureza Carlos Anwandter, no município de San Jose de La Mariquina, há cinco quilômetros do aeroporto Pichoy, na Região dos Rios, Chile. A zona apre- 
senta um complexo hidrográfico importante, destacando-se os rios Cruzes e Pichoy, que limitam com todo o território, e o rio Collimaico, pelo lado oeste, que atravessa de norte a sul a localidade, constituindo-se um referente hidrográfico secundário que outorga a esta a condição de ilha.

Historicamente esta foi uma zona de intenso tráfico comercial, tanto por via terrestre como fluvial. Parte importante das comunicações e expedições comerciais da população costeira do norte da província de Valdivia transitavam a cavalo para o rio Cruzes e depois em embarcações para chegar a Valdivia, onde se faziam as operações comerciais.

Figura 1: Mapa de localização geográfica da comunidade.

Fonte: Escaner Cultural: Revista Virtual de Arte Contemporáneo y Nuevas Tendencias, Año 8, n. 88, 2006.

A população de Tralcao se manteve durante o século vinte como um enclave agrícola cuja população combinava diversos cultivos, incluindo árvores frutíferas, junto a uma pecuária menor para a subsistência. No ano 2005, a comunidade de Tralcao estava esperançosa pelo desenvolvimento do ecoturismo, iniciativa que beneficiaria a oitenta famílias através do Projeto Fortalecimento da Identidade Cultural, Melhoramento da Gestão Ecoturística e Habilitação em Inovação Tecnológica para o uso Sustentável dos Recursos Naturais, vinculado ao Programa Ecorregião Os Lagos Sustentáveis, que levava adiante um processo de Agenda Local 21 na região. O núcleo cen- 
Culturas originárias e turismo: uma experiência de turismo comunitário no mundo Mapuche, Tralcao, Sul do Chile.

tral da proposta turística se propôs em relação à existência de uma grande variedade de avifauna no Santuário, representada emblematicamente pelo cisne de pescoço preto (Cygnus melancoryphus). A construção de um mirante para aproveitar a vista das espécies que o habitam marca, desde o ponto de vista da identidade, a relação que a população local tem com o sistema fluvial. No entanto, ao momento de iniciar a implementação do projeto, houve uma contaminação das águas subterrâneas e superficiais do território ${ }^{2}$, gerando uma série de dificuldades para a comunidade (SAMPAIO, 2010; HENRÍQUEZ et al., 2009; SKEWES et al., 2011).

$\mathrm{Na}$ atualidade Tralcao conta com uma população estimada entre 350 e 400 habitantes, o que corresponde aproximadamente a 110 famílias. $O$ índice de etnicidade indica que maioria da população está adscrita à etnia mapuche-huilliche. As atividades produtivas principais correspondem a economias de subsistência. A comunidade conta com uma escola que oferece ensino fundamental de $1^{\circ}$ ao $6^{\circ}$ ano básico, com aproximadamente 15 alunos. Sua sede fica junto a associação de moradores e indígena.

A comunidade de Tralcao continua, todavia, com um modo de vida intimamente associado à terra e sua biodiversidade, que lhes conecta com um mundo de ciclos, de tempos de espera e de colheita, em que a identidade se constrói comunitariamente. Atualmente, é difícil encontrar na comunidade indígena de Tralcao Mapu elementos culturais considerados puramente mapuche-huilliches. No entanto, foram redefinidos historicamente elementos próprios e inovações incorporadas as suas práticas, como o uso da medicina natural, a reutilização de algumas tecnologias apropriadas e comidas adaptadas aos cultivos tradicionais. O turismo aparece como uma atividade que congrega associativamente a um grupo da comunidade que observa no turismo uma oportunidade de gerar além de trabalho e renda, reafirmar sua identidade, inclusive, durante os últimos anos se criou "a festa da cereja", principal evento que congrega a diferentes atores da comunidade e visitantes.

\section{Convivencialidade e cotidianidade: intercâmbio de saberes, ensinos e aprendi- zagens em Tralcao}

O trabalho aqui descrito retoma ações empreendidas durante o ano de 2005, período em que se realiza a primeira aproximação e trabalho conjunto entre a comunidade de Tralcao e estudantes do PHMA/UACH, junto com estudantes de Antropologia e Turismo.

Como se explica na metodologia realizou-se um percurso a partir do transecto. O percurso incluiu pontos turísticos que a comunidade considera como atrativos, na ocasião que se tem visitantes. Durante o percurso (Figura 2), mencionaram-se problemas, projetos e atividades em curso na comunidade. 
Zuñiga, C.E.H.; Vera, M.P.; Skewes, J.C.; Sampaio, C.A.C.

Figura 2: O sentido do transecto realizado.

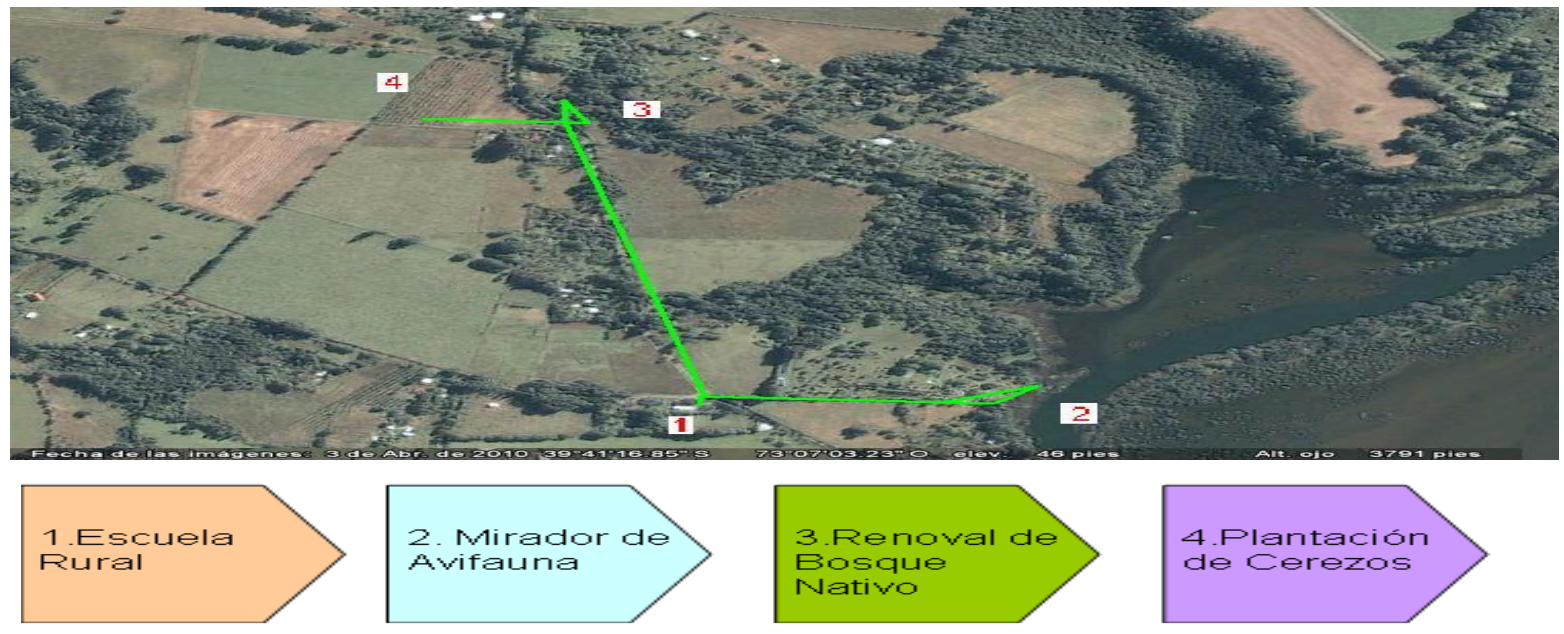

Fonte: Henríquez e Castillo (2011).

Durante o percurso relata-se a situação inicial traumática, a tragédia ambiental produzida pelo desaparecimento dos cisnes de pescoço negro, até então o principal atrativo paisagístico da localidade. Inclusive, o mirante de avifauna foi construído para observar tais pássaros, espécies raras e encontradas nos ecossistemas da região, e que em decorrência da tragédia viria a ser subutilizado. A partir de então, houve a procura de uma nova identidade, onde a paisagem bem como as práticas sociais e cotidianas pudessem ser valorizadas.

O transecto realizado demonstra uma intenção subjacente, que pode ser ilustrado pela Figura 3.

Figura 3: Fluxo do Transecto.

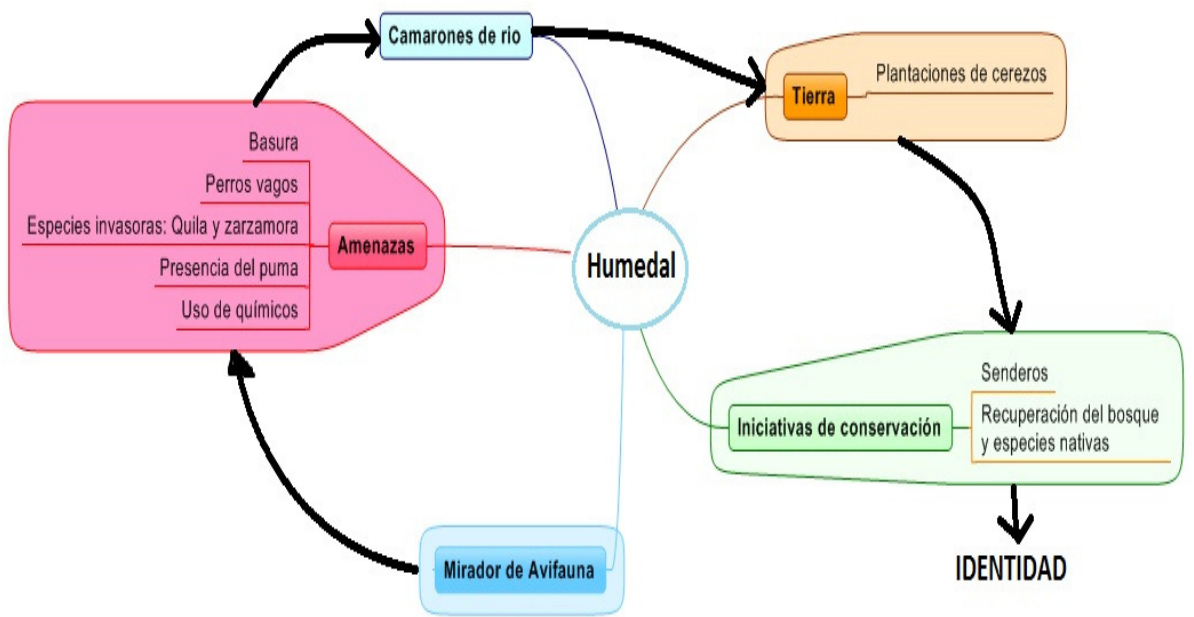

Fonte: Os autores. 
Culturas originárias e turismo: uma experiência de turismo comunitário no mundo Mapuche, Tralcao, Sul do Chile.

A intenção da trilha ecológica proposta, segundo os princípios do turismo de base comunitária, é transmitir com linguagem própria a dinâmica sistêmica da biodiversidade existente no território, podendo-se valer de uma oficina de educação ambiental, propiciado pela prática do ecoturismo. Os visitantes, geralmente professores, pesquisadores, estudantes universitários e simpatizantes com a sociobidiversidade, são potencialmente formadores de opinião. Estes além de vivenciarem uma experiência de bem estar pessoal, tomam contato com a fragilidade da sociobiodivesidade quando esta é ignorada e, por sua vez, acabam se interessando pelo movimento para a conservação dos modos de vida tradicionais e preservação da biodiversidade no território mapuche.

\section{Grupos de trabalho}

Frente aos problemas identificados e priorizados junto à comunidade, se organizaram seis grupos de trabalho (GTs). Durante uma manhã cada um destes grupos discutiu possíveis alternativas que poderiam ser implantadas na comunidade de Tralcao em resposta aos principais problemas identificados. Posteriormente, se apresentou a proposta de cada GT e partiram para a execução, descritas a seguir. Os projetos se realizaram no período de outubro a dezembro de 2010.

\section{Melhoramento do Mirante de avifauna}

Este grupo de trabalho (GT) esteve composto por estudantes de kinesiología, jornalismo, engenharia em conservação de recursos naturais e arquitetura. Como o título do projeto sugere, o objetivo do trabalho realizado se centrou na melhora do mirante de avifauna, próximo do porto de Tralcao, localizado na comunidade na borda do rio Pichoy. O mirante de avifauna está localizado em parte no Santuário da Natureza Carlos Adwanter que sofreu diretamente com as consequências da contaminação ambiental. A atividade que se desenvolve promove a tomada de consciência dos visitantes de como projetos de caráter antrópico, com finalidade privada, coloca em risco a natureza quando não se tem um estudo complexo de impacto ambiental.

\section{Melhoramento da sinalização e habilitação de uma área para picnic}

Este GT esteve composto por estudantes de kinesiologia, ciências biológicas, antropologia e engenharia em obras civis. Este trabalho se realizou em sincronia e complementarmente com o descrito anteriormente. Teve como objetivo melhorar a sinalização existente na comunidade com o fim de orientar e guiar melhor aos visitantes quando estes estão na comunidade. Instalou-se um letreiro na localidade com a impressão Bem-vindos a Tralcao, em espanhol e mapudungun - devido às raízes mapuche-huilliche que caracterizam aos habitantes do lugar. Implantou-se também, contíguo ao mirante, uma mesa e assentos que permitem os visitantes realizarem picnics.

\section{Elaboração de uma logomarca de Tralcao}

Este GT esteve composto por estudantes de antropologia, arquitetura e educação física. O GT realizou uma recompilação icônica que permitiu unificar elementos que resultassem de maior representatividade por parte da própria comunidade. Desta 
maneira este trabalho possibilitou que o GT conhecesse elementos da identidade que os participantes da comunidade reconhecem como simbólicos e com os quais se trabalhou na elaboração de um pictograma que pudesse ser utilizado como logo "imagem" da comunidade de Tralcao, conforme ilustra a Figura 4. O GT pôde identificar os elementos iconográficos dos quais destacam a cereja - tema da principal festa na localidade, o Santuário da Natureza Carlos Adwanter, o cisne de pescoço negro (Cygnus melancoryphus), a água e o fogão mapuche.

Figura 4: Logo de Tralcao.

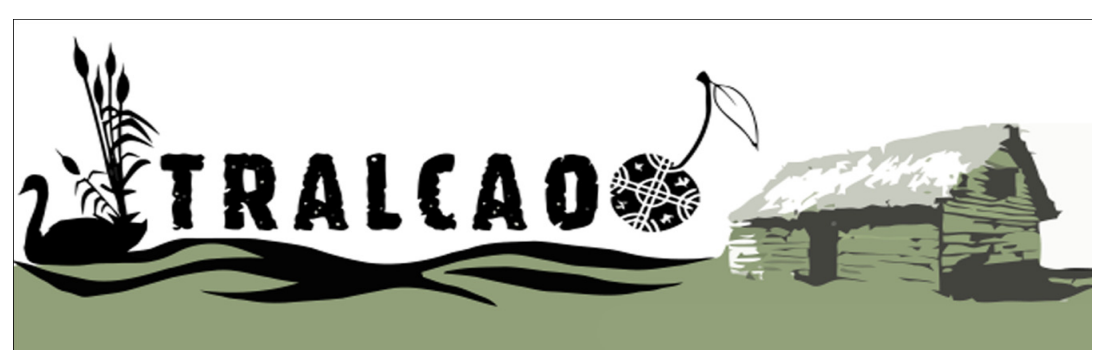

Fonte: Cuevas et al. (2010).

O fogão mapuche ou kutralwe localiza-se no centro de uma ruca (habitação mapuche $)^{3}$, construído a partir de arranjos de pedras no chão (tal como se conhece no Brasil por fogo de chão), onde se faz o fogo para cozinhar, reunir a família e esquentar-se nos dias de inverno. No entanto, há um significado cultural singular. $\mathrm{O}$ fogão é o centro da vida familiar cotidiana mapuche. Ao amanhecer, em torno do fogo, se narram os sonhos. A fumaça é o vínculo trascendental que dissolve a má sorte e assegura a energia positiva. Dado a intensa congregação ao redor do fogo, a experiência fica gravada na memória dos mapuches, constituindo-se um rito ontológico de união e de pertencia ao território (CHIHUAILAF 1999; COLIPÁN 2003).

Implantação de uma área para "compost"

Especificamente este trabalho contou com a participação de estudantes de antropologia, pedagogia, língua Inglesa e jornalismo. A compostagem pode ser entendida como um processo de produção de adubo orgânico, chamado compost, originado da decomposição da matéria orgânica, proveniente de alimentos e refugos de animais que colocados num recipiente (composteira), na qual se adiciona folhas de árvores, e com umidade adequada se obtém, depois de três meses, adubo orgânico que pode ser utilizado como fertilizante.

Proposta de lixeiras a partir de garrafas plásticas?

A proposta de construção de lixeiras esteve a cargo de um GT composto por estudantes do ensino médio, originados de diferentes colégios do município de Valdivia. O projeto surge a partir de um dos problemas encontrados na comunidade, que é a acumulação de lixo em alguns pontos. Surge assim a ideia deste GT que elabora e propõe à comunidade um protótipo de lixeiras circulares feitos com garrafas plásticas, tecido e arame. 
Culturas originárias e turismo: uma experiência de turismo comunitário no mundo Mapuche, Tralcao, Sul do Chile.

\section{Proposta de Vídeo Promocional}

Por último, resultado de um GT composto por estudantes do ensino fundamental, assistidos por um antropólogo, no qual se realizaram visitas de campo para colher informações, imagens e sons de maneira que pudesse criar um vídeo promocional. A posteriori, trabalharam na sua edição final.

\section{Considerações Finais}

O caso de Tralcao, pequena localidade imbricada no Santuário da Natureza do Rio Cruzes, na Região dos Rios, ao sul de Chile, é um caso eloquente no qual cursos de água são o marco de um conflito de interesses.

O Santuário da Natureza Carlos Andwanter é parte da bacia do rio Valdivia e corresponde a um mangue cujas águas e suas bordas serviram para a reprodução do cisne de pescoço negro (Cygnus melancoryphus), ave emblemática da zona e que gerou expectativas na população local para prática de um ecoturismo de interesse especial nesta espécie, alternativa vislumbrada a partir de uma Agenda 21 local consensuada, que possibilitou a melhora da qualidade de vida para a população local. No entanto, a partir de uma tragédia ambiental que pôs fim ao ciclo reprodutivo desta espécie emblemática se viu interrompido tal possibilidade.

Contudo, a partir desse cenário negativo, o eixo articulador do turismo de base comunitária (TBC) se sustentou a partir da hospitalidade e cotidianidade indígena, na qual se deseja conservar seus modos de vida e preservar a biodiversidade territorial, construindo de maneira solidária propostas de turismo como alternativa para resgatar, difundir e conservar o mundo mapuche. O caso de Tralcao ilustra como atividades socioprodutivas da comunidade Mapuche, tradicionais ou não, impactam socioambientalmente, sobretudo a partir das paisagens que circundam a bacia hidrográfica, e como esta relação pode servir pedagogicamente para um projeto de educação ambiental, traduzido numa proposta de TBC, no qual tem como principal atrativo a cosmovisão mapuche.

O TBC se vale de três princípios complementares - comunidade, convivialidade e cotidianidade. $O$ primeiro resgata o sentido de vizinhança, o segundo de alteridade e o terceiro de território. Ao mesmo tempo não se deseja transformar comunidades em aldeias paradisíacas, no sentido de espetacularizá-las, para agradar visitantes. O TBC pode ser utilizado como um arranjo pedagógico que melhor qualifica a educação ambiental, no sentido de formar cidadãos proativos, ao contrário de seres passivos, utilizando-se de trilhas interpretativas de paisagens naturais associadas a paisagens construídas.

A educação ambiental nestes moldes privilegia uma convivência respeitosa entre culturas, no sentido filosófico de alteridade, no qual se possa compreender um modo de vida, de produção e de conhecimento melhor quando se passa a conhecê-los. Contrário à perspectiva da cultura dominante na ocasião que se propõe e atua como se tivesse muito a ensinar e que os dominados muito a aprender. 
A partir deste trabalho, sugere-se que o enfoque do TBC pode ser aplicado, inclusive, em tipologias convencionais de turismo, nas quais querem se ajustar sob o signo de turismo comunitário, solidário e sustentável, no qual a inclusão e responsabilidade socioambiental potencializa a imagem associada ao destino turístico que se deseja adequar.

\section{Referências Bibliográficas}

ALONQUEO, M. Instituciones religiosas del pueblo mapuche. Santiago: Nueva Universidad, 1979.

BAUMAN, Z. Comunidade: a busca por segurança no mundo atual. Rio de Janeiro: Zahar, 2003.

CA-CiAmb - Comitê de Área em Ciências Ambientais / Coordenadoria de Aperfeiçoamento de Pessoal do Ensino Superior (CAPES)/Ministério da Educação. Documento de área da CA-CiAmb (versão preliminar), Brasília, 2011. prelo

CASTILLO, Y.; HENRIQUEZ, C.; SKEWES, J.C. Co-inspirando en desarrollo y sustentabilidad desde los indicadores socioambientales participativos. Anales del Coloquio Colonilidad/decolonialidad del poder saber: miradas desde el sur. Universidad austral de Chile, 2011.

CHIHUAILAF, E. Recado confidencial a los chilenos. Santiago: LOM, 1999.

COLIPÁN, B. Identidades, memoria y alegorías. In: MONTECINO, S. Revisitando Chile: identidades, mitos e historias. Santiago: Publicaciones del Bicentenario, p. 457462. 2003.

CORIOLANO, L. N.; LIMA, L. C. (org.). O turismo e a relação sociedade-natureza. Fortaleza: EDUECE, 2007.

CROSBY, A.; PRATO, N. Fundamentos y retos del turismo rural. In: CROSBY, A. (ed.) Re-inventando el turismo rural. Barcelona: Laertes S.A, 2009.

CUEVAS, R.; HERRERA, C.; HUENCHULEO, V.; Lefian, A. En búsqueda de una proyección simbólica para Tralcao. Trabajo de conclusión del curso Filosofías del Desarrollo: de la crítica a las ideas y de las ideas a la práctica, Programa de Honor en medio Ambiente y Desarrollo Universidad Austral de Chile. Segundo semestre, 2010.

FOERSTER, R. Introducción a la religiosidad Mapuche. Santiago: Universitaria, 1993.

GADGIL, M. Participatory local level assessment of life support systems: a methodology manual. Centre for Ecological Sciences. Indian Institute of Science. Technical Report, n. 78, apr., 2000. 
Culturas originárias e turismo: uma experiência de turismo comunitário no mundo Mapuche, Tralcao, Sul do Chile.

GREBE, M. E. Algunos paralelismos en los sistemas de creencias mapuches: los espíritus del agua y de la montaña. Cultura-Hombre-Sociedad III (2): 143-154, 1986.

GREBE, M. E. El subsistema de los ngen en la religiosidad Mapuche. Revista Chilena de Antropología,12: 45-64, 1993-4.

GREBE, M. E. Relaciones hombre-naturaleza en la cultura Mapuche. los Ngen: sus Implicancias y proyecciones socioculturales. In: IX Jornada de Alternativas Religiosas en América Latina, Buenos Aires, 2000. Anales ..., Buenos Aires, 2000.

HENRÍQUEZ, C.; SAMPAIO, C.; LYON, V.; OYARZÚN E. Turismo comunitario y sustentabilidad en Tralcao, Mariquina (Chile): interconectando preservación ambiental, gestión ecoturística y fortalecimento de la identidad cultural en una experiencia de agenda local 21. Anuario Turismo y Sociedad, n. 10, p. 17-29, 2009.

HEMRIQUEZ, C.; PILQUIMAN, M.; SKEWES, J. C. Turismo comunitario o de base comunitaria: una experiencia alternativa de hospitalidad vivida en el mundo mapuche. Tralcao sur de Chile. In: VIII Seminário da Associação Nacional Pesquisa e PósGraduação em Turismo 02 e 04 de outubro de 2011 -- UNIVALI - Balneário Camboriú/SC. Anais ..., Balneário Camboriú, 2011.

ILLICH, I. A convivencialidade. Lisboa: Europa-América, 1976.

IRVING, M. A.; AZEVEDO, J. Turismo: o desafio da sustentabilidade. São Paulo. Editora Futura, 2002.

LIMA, C. M. D. de. O imaginário sobre o trabalho e suas representações no cotidiano dos comerciantes do mercado público em Pernambuco. Ciências \& Cognição, v. 3 , pp. 10-20, 2004.

PILQUIMÁN V., M.; SKEWES V., J. C. Los paisajes locales y las encrucijadas del etnoturismo: Reflexiones a partir de los proyectos turísticos de comunidades indígenas de la Región de los Lagos en Chile. Cuadernos de Turismo, n. 24, p. 169191, 2009.

PILQUIMÁN V., M.; SKEWES V., J. C. Relatos en torno al etnoturismo: La comunidad indígena de Choroy-Traiguén, Provincia de Osorno, y sus proyectos de desarrollo. Revista Líder, n. 16, p. 105-124, 2010.

SAMPAIO, C. A. C. Turismo como fenômeno humano: princípios para se pensar a socioeconomia. Santa Cruz do Sul: EDUNISC, 2005.

SAMPAIO, C.. A. C. (Org.). Gestão que privilegia uma outra economia: ecossocioeconomia das organizações. Blumenau: EDIFURB, 2010. 
SEIXAS, C. S. Abordagens e técnicas de pesquisa participativa em gestão de recursos naturais. In: VIEIRA, P. F. F.; BERKES, F.; SEIXAS, C S. (Org.). Gestão integrada e participativa de recursos naturais. Florianópolis: Secco/APED, 2005.

SKEWES, J. C.; GUERRA, D.; HENRÍQUEZ C.; PILQUIMAN, M. Culturas originarias y turismo: espacios interdisciplinarios e interculturales para la recuperación del paisaje en el mundo mapuche (Tralcao, Sur de Chile). II Congreso Internacional de Gestión Cultural. Mar del Plata, 25 - 27 de agosto de 2011. Anales. Mar del Plata, 2011.

SKEWES, J. C.; GUERRA, D.; ROJAS, P.; MELLADO M. ¿La memoria de los paisajes o los paisajes de la memoria? Los enigmas de la sustentabilidad socioambiental en las geografías en disputa. Desenvolvimento e Meio Ambiente, 23: 39-57, 2011.

SMITH, V. Anfitriones e invitados. Madrid: Endymion, 1992.

UACH, UNIVERSIDAD AUSTRAL DE CHILE. Primer informe de avance: estudio sobre el origen de mortalidad y disminución poblacional de aves acuáticas en el santuario de la naturaleza Carlos Anwardter, en la provincia de Valdivia. Convenio Complementario Especifico n. 1210 - 1203/2004-11-14, 15/diciembre/2004, Dirección Regional CONAMA X Región de Los Lagos. Valdivia: UACH, 2005.

\section{Notas}

${ }^{1}$ Este trabalho é resultado do projeto do Fondo Nacional (Chile) de Desarrollo Científico y Tecnológico (Fondecyt) 1090465: "Los paisajes del agua".

${ }^{2}$ Muitos cisnes morreram lentamente de fome devido a redução do luchecillo (Egeria densa), fonte principal de sua alimentação, devido às altas concentrações de sulfato evacuadas por uma indústria de celulose que fez diminuir o bicarbonato de cálcio necessário para que se obtenha dióxido de carbono [CO2], o que permite realizar a fotossíntese (UACH, 2005).

${ }^{3} \mathrm{Na}$ floresta ao lado de um curso d’água, os mapuches construíam suas habitações. Estas eram chamadas de rucas, ranchos de telhado de palha. Não tinham janelas. A porta estava orientada para a saída do sol, desta forma se determinava e controlava o tempo e o movimento deste no percurso de um ano (CHIHUAILAF 1999; COLIPÁN 2003).

\section{Agradecimentos}

* Conselho Nacional de Desenvolvimento Científico e Tecnológico (CNPq).

* Aos e as estudantes do curso Filosofia do Desenvolvimento (2ำ Semestre 2010) do Programa de Honra em Meio Ambiente e Desenvolvimento Humano Sustentável da Universidade Austral de Chile (PHMA-UACh). 
Culturas originárias e turismo: uma experiência de turismo comunitário no mundo Mapuche, Tralcao, Sul do Chile.

Christian Eduardo Henríquez Zuñiga: Universidade Austral de Chile, Santiago, Chile.

Email: christianhen@gmail.com

Link para o currículo Lattes: http://lattes.cnpq.br/4912018813956067

Marisela Pilquiman Vera : Universidade Autônoma de Madrid, Madrid, Espanha.

Email: mariselapilquiman@yahoo.com

Juan Carlos Skewes: Universidade Alberto Hurtado, e Universidade Austral de Chile, Santiago, Chile.

Email: skewes.juancarlos@gmail.com

Link para o currículo: http://www.conicyt.cl/bases/fondecyt/personas/2/7/27368.html

Carlos Alberto Cioce Sampaio: Universidade Federal do Paraná, Curitiba, PR, e Universidade Regional de Blumenau, Blumenau, SC, Brasil.

Email: carlos.cioce@gmail.com

Link para o currículo Lattes: http://lattes.cnpq.br/9034603212802471

Data de submissão: 21 de outubro de 2011

Data de recebimento de correções: 25 de janeiro de 2012

Data do aceite: 27 de janeiro de 2012

Avaliado anonimamente 